Timothy Mott, MD; David Echeverri, MD; Luke Fondren, DO; Ashley Hunter, MD South Baldwin Regional Medical Center Family Medicine Residency,

Foley, AL

DEPUTY EDITOR Anne Mounsey, MD Department of Family Medicine, University of North Carolina, Chapel Hill doi: $10.12788 / \mathrm{jfp} .0174$

\title{
Confidently rule out CAP in the outpatient setting
}

\author{
A focus on specific signs and symptoms-without \\ imaging-may rule out community-acquired pneumonia \\ in outpatients.
}

\section{PRACTICE CHANGER}

You can safely rule out community-acquired pneumonia (CAP)-without requiring a chest $\mathrm{x}$-ray-in an otherwise healthy adult outpatient who has an acute cough, a normal pulmonary exam, and normal vital signs using this simple clinical decision rule (CDR). ${ }^{1}$

STRENGTH OF RECOMMENDATION

A: Based on a systematic review of prospective case-control studies and randomized controlled trials in the outpatient setting. ${ }^{1}$

Marchello CS, Ebell MH, Dale AP, et al. Signs and symptoms that rule out community-acquired pneumonia in outpatient adults: a systematic review and meta-analysis. J Am Board Fam Med. 2019;32:234-247.

\section{ILLUSTRATIVE CASE}

An otherwise healthy 56-year-old woman presents to the emergency department (ED) with a productive cough of 4 days' duration. A review of her history is negative for recurrent upper respiratory infections, smoking, or environmental exposures. Her physical exam is unremarkable and, more specifically, her pulmonary exam and vital signs (temperature, respiratory rate, and heart rate) are within normal limits. The patient states that last year her friend had similar symptoms and was given a diagnosis of pneumonia. Is it necessary to order a chest $\mathrm{x}$-ray in this patient to rule out community-acquired pneumonia (CAP)?

AP is a common pulmonary condition seen in the outpatient setting in the United States, representing more than 4.5 million outpatient visits in the years 2009 to $2010 .^{2}$ Historically, a diagnosis of CAP has been based on clinical findings in conjunction with infiltrates seen on chest x-ray.

In 2017, more than 5 million visits to the ED were due to a cough. ${ }^{3}$ The use of radiographic imaging in EDs has been increasing. There were 49 million x-rays and 2.7 million noncardiac chest computed tomography (CT) scans performed in 2016, many of which were for patients with cough. ${ }^{3,4}$ Although imaging is an extremely useful tool and indicated in many instances, the ability to rule out CAP in an adult who presents with a cough by using a set of simple, clinically based heuristics without requiring imaging would help to increase efficiency, limit cost, and decrease exposure of patients to unnecessary and potentially harmful diagnostic studies.

Clinical decision rules (CDRs) are simple heuristics that can stratify patients as either high risk or low risk for specific diseases. Two older large, prospective cross-sectional studies developed CDRs to determine the probability of CAP based on symptoms (eg, night sweats, myalgias, and sputum production) and clinical findings (eg, temperature $>37.8^{\circ} \mathrm{C}\left[100^{\circ} \mathrm{F}\right]$, tachypnea, tachycardia, rales, and decreased breath sounds)..$^{5,6}$ This meta-analysis includes these studies and more recent studies ${ }^{7-9}$ used to develop a CDR that focuses solely on a few specific signs and symptoms that can reliably rule out CAP without imaging, and so prove highly useful for busy primary care clinicians. 


\section{STUDY SUMMARY}

\section{This simple approach rules out CAP in outpatients $99.6 \%$ of the time}

This systematic review and meta-analysis included studies that used 2 or more signs, symptoms, or point-of-care tests to determine the patient's risk for CAP. ${ }^{1}$ Twelve studies $(\mathrm{N}=10,254)$ met inclusion criteria by applying a CDR to adults or adolescents presenting with respiratory signs or symptoms potentially suggestive of CAP to either an outpatient setting or an ED. Prospective cohort, cross-sectional, and case-control studies were included when a chest x-ray or CT was utilized as the primary reference standard. Exclusion criteria included studies of military or nursing home populations and studies in which the majority of patients had hospital- or ventilator-associated pneumonia or were immunocompromised.

A simple, highly useful CDR emerged from 3 of the studies $(\mathrm{N}=1865))^{7-9}$ Two of these studies were described as case-control studies with prospective enrollment of patients older than 17 years in both outpatient and ED settings. ${ }^{7,8}$ One study was conducted in the United States (mean age, 65 years) and the other in Iran (mean age, 60 years). The third was a Chilean prospective cohort study of ED patients older than 15 years (mean age, 53 years). ${ }^{9}$ In each of these studies, the outpatient or ED physicians collected all clinical data and documented their physical exam prior to receiving the chest radiograph results. The radiologists were masked to the clinical findings at the time of their interpretation.

I Results. From the meta-analysis, a simple CDR emerged for patients with normal vital signs (temperature, respiratory rate, and heart rate) and a normal pulmonary exam that virtually ruled out CAP (sensitivity $=96 \%$; 95\% CI, 92\%-98\%; and negative likelihood ratio $=0.10$; $95 \% \mathrm{CI}, 0.07-0.13)$. In patients presenting to an outpatient clinic with acute cough with a $4 \%$ baseline prevalence rate of pneumonia, this CDR ruled out CAP $99.6 \%$ of the time.

\section{WHAT"S NEW}

\section{A clinical decision rule validated for accuracy}

This is the first validated CDR that accurately rules out CAP in the outpatient or ED setting using parameters easily obtainable during a clinical exam.

\section{CAVEATS}

\section{Proceed with caution in the young and the very old}

Two of the 3 studies in this CDR had an overall moderate risk of bias, whereas the third study was determined to be at low risk of bias, based on appraisal with the Quality Assessment Tool for Diagnostic Accuracy Studies (QUADAS-2) framework. ${ }^{10}$

The mean age range in these 3 studies was 53 to 66 years (without further data such as standard deviation), suggesting that application of the CDR to adults who fall at extremes of age should be done with a modicum of caution.

Additionally, although the symptom complex of COVID-19 pneumonia would suggest that this CDR would likely remain accurate today, it has not been validated in patients with COVID-19 infection.

\section{CHALLENGES TO IMPLEMENTATION}

\section{Potential reluctance \\ to forgo imaging}

Beyond the caveats regarding COVID-19, the use of a simple CDR to reliably exclude pneumonia should have no barrier to implementation in an outpatient primary care setting or ED, although there could be reluctance on the part of both providers and patients to fully embrace this simple tool without a confirmatory chest x-ray.

JFP

\section{ACKNOWLEDGEMENT}

The PURLs Surveillance System was supported in part by Grant Number UL1RR024999 from the National Center for Research Resources, a Clinical Translational Science Award to the University of Chicago. The content is solely the responsibility of the authors and does not necessarily represent the official views of the National Center for Research Resources or the National Institutes of Health.

Copyright @ 2021. The Family Physicians Inquiries Network. All rights reserved.

\footnotetext{
References

1. Marchello CS, Ebell MH, Dale AP, et al. Signs and symptoms that rule out community-acquired pneumonia in outpatient adults: a systematic review and meta-analysis. J Am Board Fam Med. 2019;32:234-247.
}

For adult outpatients who present with acute cough, this clinical decision rule can quickly and accurately rule out CAP without the need for diagnostic imaging. 
2. St Sauver JL, Warner DO, Yawn BP, et al. Why patients visit their doctors: assessing the most prevalent conditions in a defined American population. Mayo Clin Proc. 2013;88:56-67.

3. CDC. National Center for Health Statistics. National Hospital Ambulatory Medical Care Survey: 2017. Emergency Department Summary Tables. Accessed March 24, 2021. www.cdc.gov/nchs/ data/nhamcs/web_tables/2017_ed_web_tables-508.pdf

4. Jain S, Self WH, Wunderink RG, et al; CDC EPIC Study Team. Community-acquired pneumonia requiring hospitalization among US adults. $N$ Engl J Med. 2015;373:415-427.

5. Heckerling PS, Tape TG, Wigton RS, et al. Clinical prediction rule for pulmonary infiltrates. Ann Intern Med. 1990;113:664-670.

6. Diehr P, Wood RW, Bushyhead J, et al. Prediction of pneumonia in outpatients with acute cough-a statistical approach. JChronic Dis. 1984;37:215-225.

7. O'Brien WT Sr, Rohweder DA, Lattin GE Jr, et al. Clinical indica- tors of radiographic findings in patients with suspected community-acquired pneumonia: who needs a chest x-ray? J Am Coll Radiol. 2006;3:703-706.

8. Ebrahimzadeh A, Mohammadifard M, Naseh G, et al. Clinical and laboratory findings in patients with acute respiratory symptoms that suggest the necessity of chest x-ray for communityacquired pneumonia. Iran J Radiol. 2015;12:e13547.

9. Saldías PF, Cabrera TD, de Solminihac LI, et al. Valor predictivo de la historia clínica y examen físico en el diagnóstico de neumonía del adulto adquirida en la comunidad [Predictive value of history and physical examination for the diagnosis of communityacquired pneumonia in adults]. Abstract in English. Rev Med Chil. 2007;135:143-152.

10. Whiting PF, Rutjes AWS, Westwood ME, et al; QUADAS-2 Group. QUADAS-2: a revised tool for the quality assessment of diagnostic accuracy studies. Ann Intern Med. 2011;155:529-536.
This supplement was sponsored by Boehringer Ingelheim Pharmaceuticals, Inc. It was edited and peer reviewed by The Journal of Family Practice.

\section{Type 2 Diabetes 2021}

The management of type 2 diabetes (T2D) has changed substantially over the last several decades. Standard practices have moved away from the glucocentric approach of T2D management into an era in which the interplay among T2D, obesity, atherosclerotic cardiovascular disease, heart failure, and chronic kidney disease is increasingly recognized.

This supplement to The Journal of Family Practice brings together key updates in the field of T2D to help physicians care for patients who have not only T2D, but other interrelated diseases.

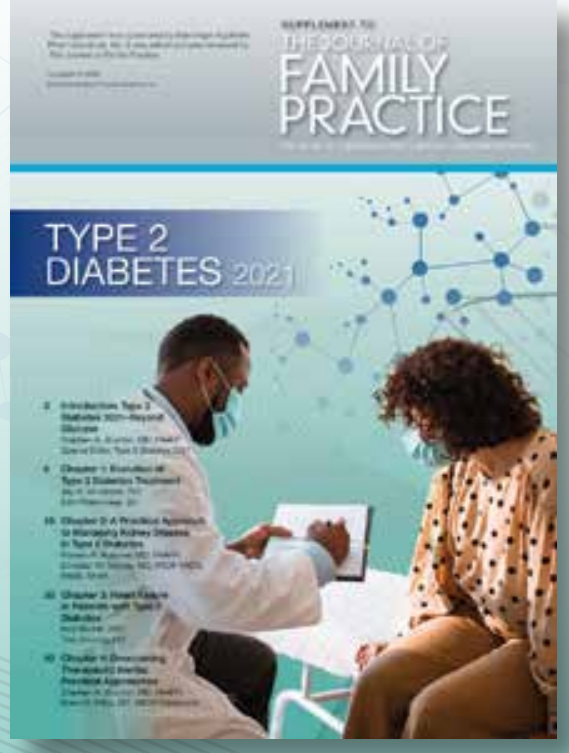

This supplement can be found at www.mdedge.com/T2D2021. 